\title{
25 Research Square

\section{Trend And Associated Factors Of Cesarean Section Rate In Ethiopia: Evidence From 2000-2019 Demographic And Health Survey}

Rahel mezemir Abebe ( $\sim$ rahelmezemir7@gmail.com )

Pan African University Life, University of Ibadan

Oladapo 0. Olayemi

Pan African University Life, University of Ibadan

\section{Yadeta Dessie Bacha}

Haramaya University

\section{Research Article}

Keywords: cesarean section delivery, rural, trend, Ethiopia

Posted Date: March 3rd, 2022

DOI: https://doi.org/10.21203/rs.3.rs-1386764/v1

License: (c) (i) This work is licensed under a Creative Commons Attribution 4.0 International License. Read Full License 


\section{Abstract}

Background: The world health organization (WHO) considers cesarean section (CS) prevalence of less than $5 \%$ suggests an unmet need. On the other hand, a prevalence of more than 15\% may pose to risk to mother-and-child; however, Ethiopia was much lower than the aforementioned level. Therefore, this study aimed to determine the trend of CS, and factors that influence it

Methods: Secondary analysis of the 2000-2019 Ethiopia demographic and health survey (EDHS) was used. The trend over 1995-2019 was assessed for the rural and urban areas using the Extended Mantel-Haenszel chi-square test; whereas, factors for CS were identified based on DHS 2016 data. A multi-level logistic regression analysis technique was used to identify the factors associated with CS. The analysis was adjusted for the different individual- and community-level factors affecting cesarean section delivery. Data analysis was conducted using STATA 14.1 software.

Result: CS rate increased significantly from $5.1 \%$ in 1995 to $16 \% 2019$ in urban area and 0.001 in 1995 to $3 \% 2019$ in rural area. The overall increment of CS rate was $0.7 \%$ in 1995 to $6 \%$ in 2019. The odds of CS rate was higher among women of age $25-34$ years $(A O R=2.79 ; 95 \% \mathrm{Cl}: 1.92,4.07)$ and women of age $34-49$ years $(A O R=5.23 ; 95 \%$ $\mathrm{Cl}: 2.85,9.59)$, women of secondary education (AOR=2.01; $95 \% \mathrm{Cl}: 1.17,3.56)$ and higher education $(\mathrm{AOR}=4.12 ; 95 \%$ Cl: 2.33-7.29), multiple pregnancies ( $A O R=11.12 ; 95 \% \mathrm{Cl}: 5.37,23$. ), obese women ( $\mathrm{AOR}=1.73 ; 95 \% \mathrm{Cl}: 1.22,2.45)$, urban residence (AOR=2.28; /95\% Cl: 1.35-3.88), and women of antenatal care visit (ANC) $>4(A O R=3.34 ; 95 \% \mathrm{Cl}$ : $1.12,4.58)$. Whereas, the odds of cesarean section lower among parity of $2-4$ children $(A O R=0.54 ; 95 \% \mathrm{Cl}: 0.37$, $0.80)$.

Conclusion: In Ethiopia, the CS rate is below the level recommended by WHO, especially in rural residence, thus, intervention efforts need to be prioritized for women living in a rural area, empowering women's education, encouraging co-services such as ANC usage.

\section{Introduction}

In obstetrical care, Caesarean section (CS) is the most routinely performed surgery. It is the delivery of a fetus through a surgical incision in a pregnant woman's abdominal wall and uterine wall (1). it is commonly done for maternal or fetal reasons to avert maternal and neonatal morbidity and mortality rate(2). Globally, the use of cesarean section among delivery women has continuously increased, and it is predicted to continue to rise over the next decade, in both developed and developing countries (3), although, the availability of safe Cesarean sections in the resource-limited country is still much lower (4). Recent data from 154 countries showed that the global average CS rate of $21.1 \%$, with averages of $8.2 \%$ at least, $24.2 \%$ in less, and $27.2 \%$ in more developed countries. Sub-Saharan Africa has the lowest rates (5.0 percent, 39 nations, 88.6 percent birth coverage), while, Latin America and the Caribbean have the highest rates (42.8 percent, 23 countries, 91.2 percent birth coverage (4). The world health organization considers CS prevalence of less than $5 \%$ suggests an unmet need. On the other hand, a prevalence of more than $15 \%$ may pose to risk to mother-and-child (5). Report from the population-based study, cesarean section rates greater than roughly $10 \%$ in the population are not associated with lower maternal and neonatal mortality rates (6). Another ecological study found a negative and statistically significant linear correlation between CS rate the number of CS deliveries per 100 births and neonatal mortality(7). Despite all of these facts over the recent years, the medically and non-indicted CS section is significantly practiced (8). Evidence from the WHO survey shows this worldwide increase of medically and non-indicated cesarean sections can have a substantial impact on a woman's health and medical costs like increased rate of infection, longer healing time, significant bleeding, increased 
iatrogenic injury, increased breathing difficulties, and even death $(9,10)$. Similarly, a multi-country facility-based survey came to the same conclusion(3)

Several studies show medical and non-medically indicated factors including the type of health institution, sociodemographic characteristics, and maternal health of women, have been linked to an increase in CS. Some of these factors are maternal age, birth order, place of residence, socioeconomic status, maternal educational level, previous CS, obstetric problems, maternal request, and income level(10-13). These variables also differ depending on the population(14)

In Ethiopia, research from the available resource on the prevalence of CS indicates a figure well below the WHO's recommended threshold of $10 \%(5)$. Furthermore, for numerous years there has been no notable increase in the country's population-based CS rates. For example, in the 2016 and 2000 Ethiopia Demographic and Health Surveys (EDHS), national CS rates were found to be very low (1.9 percent and 0.7 percent, respectively) $(15,16)$. This figure is lower than that of several African countries, including Ghana( 13\% in 2014)(17), Nigeria (2.1\% in 2013)(18), Mozambique (4.7\%in 2014)(19). The relatively low prevalence of CS in the Ethiopian population reflects unmet demands which may contribute to the country's poor maternal and newborn outcomes(20). Evidence from hospitalbased and population-based cross-sectional studies in Ethiopia shows delivery by CS is most common in women aged 35-49, first-parity births, births order women had more than three Antenatal Care (ANC) visits, births in urban areas, higher education, and higher economic status (15\%) (21-23).

In Ethiopia, most studies on the CS section was used hospital base data. This type of data was most of the time used a small sample size and was also subject to selection bias. Few studies were used population-based data; however, the studies had some limitations. For instance, the study didn't use higher statistical software for analysis like multilevel analysis which is used to identify individual and community level factors, the studies didn't calculate over year trend analysis. Using a nationally representative sample has several advantages over other institutional sample data in terms of calculating the compiled trend to highlight national level characteristics which could lead to policy decisions at the national level. Therefore, the present study used to assess the trend of CS in the urban and rural areas and the factors influencing it

\section{Methods And Material Study setting}

The study was done in Ethiopia. Ethiopia is a multi-ethnic country in east Africa with a diverse population. It is bordered on the west by Sudan, on the east by Somalia and Djibouti, on the north by Eritrea, and on the south by Kenya. The country has a total area of $1,112,000$ square kilometers

Ethiopia is divided into eleven regions and two municipal governments. Tigray, Afar, Amhara, Oromiya, Somali, Benishangul-Gumuz, Southern Nations Nationalities and People (SNNP), Gambela, Sidama, South Western, and Harari are among the regions involved. Addis Ababa and Dire Dawa are the administrative cities(24). According to the EDHS 2016 and 2011, the prevalence of CS in Ethiopia was 1.9\% (15) and 0.7\% (25), respectively $(15,25)$.

\section{Study design}

The research was based on secondary data from the EDHS. Factors associated with CS were identified using EDHS 2016 data; whereas, trend analysis was done using EDHS 2000, 2005, 2011, 2016, 2019 (mini EDHS) data. Since EDHS collected data about births in the previous 5 years, the data indicated CS from 1995 to 2019(15). 


\section{Sample size and sampling methods}

All EDHS surveys used a sample that was aimed to represent all of the country's regions and administrative cities. The survey participants were chosen using a two-stage stratified sampling technique. The first stage was a selection of the enumeration areas. The enumeration areas were stratified into urban and rural. In the second stage, households in the selected enumeration area were selected. The sample size is allocated by using a probability proportional allocation method. 645 enumeration areas (EAs) were chosen for the 2016 DHS. There were 202 EAs from urban regions and 443 from rural areas. Six hundred twenty-four EAs were included in the 2011DHS (187 from urban and 437 from rural areas). (15). The 2005 EDHS had 540 EAs (145 from urban areas and 395 from rural areas) while the 2000 DHS included 539 EAs (138 from urban and 401 from rural) $(16,25)$. Then, on average 27 to 32 households per EA were selected from all surveys. The source population was all live births from reproductive age women within 5 years before the survey in Ethiopia. A total weighted sample of 46,317 live births (12,260 in EDHS 2000, 11,163 in EDHS 2005, 11,872 in EDHS 2011, and 11,022 in EDHS2016) were used for analysis. Detailed sampling procedure can be found from the $\operatorname{EDHS}(15,16,25,26)$.

\section{Data collection}

Five interviewers-administered questions were used by EDHS, the household questionnaire, the woman questionnaire, the men questionnaire, the biomarker questionnaire, and the health facility questionnaire $(5,16,25$,

26). The data was collected for this study from children under the age of five surveys, born to interview mothers who gave birth within five years of the survey year 1995-2016 which was included in the child records. The data collection tool was written in English initially then translated into the country's three main languages: Amharic, Oromiffa, and Tigrigna. Somaligna and Afarigna languages were also used in the 2000 DHS(5, 25).

\section{Variable of study}

\section{Outcome variable}

The outcome variable in this study is the cesarean section which was taken dichotomous and coded by the value " 1 " (one) if the respondents underwent cesarean delivery and "0" (zero) if not.

\section{Independent variable}

There were three categories of independent variables; institution-related, socio-demographic factors, socio-economic factors, and pregnancy-related factors. Institutional factors include the place of delivery (public versus private), the number of antenatal care visits (no visit, 1-3 and >4), pregnancy-related factors include parity( Primi-parous, multiparous, and Grand-multi-parous), birth order (first, second, third or higher), maternal, body mass index (normal, underweight and overweight), Size of the baby was determined from the maternal recall of baby's weight at birth (very large, average, smaller than the average), socio-demographic and socio-economic factors consist of maternal education, maternal age at birth, marital status, mothers' employment status (yes/no), wealth index (poor, middle, rich), residences, and region.

\section{Data analysis}

Completed EDHS questionnaires were meticulously tagged, entered, and modified after data collection The distribution of study participants in the sample was weighted to create nationally representative data (25). STATA software version 14 was used to analyze the data. Frequency and percentage were used as descriptive statistics. Using chi-square analysis, the CS rate was compared across several socioeconomic, maternal, and child 
characteristics. The DHS surveys gathered information on the mode of delivery of birth within the previous five years. The rate was calculated for each year between 1995 and 2019 based on the specific year of delivery. The data 2019 mini DHS data was included for the trend analysis, however, to explore the associated factors of CS the 2019 mini DHS data were not contained all the factors variables, thus, 2016 DHS was used data. The Extended MantelHaenszel chi-square test for linear trend was used to examine the significance of the trend of the CS rate using the Open Epi software (Version 3.01) dose-response program (27). A 95\% significant probability of the existence of a trend was declared when the $\mathrm{p}$-value was less than 0.05 . Further, the change in trend CS rate is presented in two ways, Absolute increase of CS rate and relative increase as the average annual rate of increase (AARI), to find absolute change increase, subtract the latest CS rate to earliest CS rate and to find an average annual rate of increase, AARI = [(an / am) [1 / (n-m)] -1 where am, is the first observation of CS rate and is the latest observation of $\mathrm{CS}$ rate, $\mathrm{m}$ is the first observed year and $\mathrm{n}$ is the latest observed year. The AARI is a geometric progression ratio that provides a constant rate of change during the study period (4).

To identify factors associated with cesarean section delivery, a Multi-level logistic regression analysis technique was applied since the data had hierarchical and clustering nature.

The four models were carried out. The first model was an empty model that was used to calculate the random variability in the intercept. The second model estimated the influence of individual-level factors on CS delivery. The third model looked at how community-level factors are associated with CS delivery. The third model examined how community-level factors influenced CS delivery. Finally, the fourth model computed the influence of individual and community-level factors on cesarean delivery. The Intra-Cluster Correlation (ICC) was determined to illustrate the correlation between clusters within a model, and the intra-cluster correlation (ICC) is expected to be $\geq 10 \%$ when using this model. The power of variables included in each model in predicting delivery was also determined using the Proportional Change in Variance (PCV).To determine the factors associated with cesarean section, the model with the highest PCV value was used. Significant factors were considered as variables with a p-value less than 0.05 .

\section{Ethical consideration}

All Ethiopian Demographic and Health Surveys obtained ethical approval from the Ethiopian Health and Nutrition Research Institute Review Board, the Ministry of Science and Technology, ICF International's Institutional Review Board, and the CDC. The data was collected after informed consent was obtained and all information was kept private. After reviewing the brief descriptions of the study provided to the DHS program, the Demographic and Health Surveys Program granted authorization to access EDHS data for this specific research. The data sets were handled with the utmost confidentiality(15).

\section{Result}

\section{Socio-demographic and economic characteristics of the study population}

In the four EDHSs', information on Caesarean Section deliveries was collected from 46,316 women who had given birth in the five years before the survey period. The median ages (interquartile range (IQR)) of women in the four surveys were similar, with the most recent (2016 DHS) being $26.1+9$ years. In all the four surveys, three -fourth of live birth were from rural areas, the latest report (2016 DHS) was $88.8 \%$. Most of the live births were from the Oromia region. On the other hand, the percentage of women having a primary education increased slightly from $13 \%$ in 2000 to $26.8 \%$ in 2016 . In all four surveys, the majority of women were married (Table 1).

Page 5/22 
Table 1

Sociodemographic and economic characteristics of the study population, finding from 2000 to 2016 DHS

\begin{tabular}{|c|c|c|c|c|c|}
\hline \multirow[t]{3}{*}{ Variable } & & Live birth in & Live birth in & Live birth in & Live birth in \\
\hline & & $\begin{array}{l}\text { 2000DHS(n = } \\
12,260)\end{array}$ & $\begin{array}{l}\text { 2005DHS }(n= \\
11,163)\end{array}$ & $\begin{array}{l}\text { 2011DHS(n= } \\
11,872)\end{array}$ & $\begin{array}{l}\text { 2016DHS(n = } \\
11,022)\end{array}$ \\
\hline & & $(\%)$ & $(\%)$ & $(\%)$ & $(\%)$ \\
\hline Mother's age at birth & $\begin{array}{l}\text { Median + } \\
\text { IQR }\end{array}$ & $26 \pm 10$ & $26 \pm 10$ & $26 \pm 9$ & $26 \pm 9$ \\
\hline \multirow[t]{11}{*}{ Regions/administrations } & Tigray & $788(6.4)$ & $698(6.3)$ & $753(6.3)$ & $716(6.5)$ \\
\hline & Afar & $126(1.0)$ & $107(1.0)$ & $121(1.0)$ & $114(1.0)$ \\
\hline & Amhara & $3202(26.2)$ & $2621(23.5)$ & $2656(22.4)$ & 2072 (18.8) \\
\hline & Oromiya & 4999(40.8) & $4411(39.5)$ & $5014(42.2)$ & $4851(44.2)$ \\
\hline & Somali & $142(1.1)$ & $477(4.3)$ & $364(3.1)$ & $507(4.6)$ \\
\hline & Ben-Gumz & $124(1.0)$ & $105(0.9)$ & $140(1.2)$ & $122(1.1)$ \\
\hline & SNNP & 2602(21.2) & $2500(22.4)$ & $2494(21.1)$ & $2296(20.8)$ \\
\hline & Gambela & $29(0.2)$ & $31(0.3)$ & $40(0.3)$ & $27(0.2)$ \\
\hline & Harari & $25(0.2)$ & $22(0.2)$ & $29(0.2)$ & $26(0.2)$ \\
\hline & Addis & 182(1.5) & $153(1.3)$ & $221(1.9)$ & $244(2.2)$ \\
\hline & Dire Dawa & $40(0.3)$ & $37(0.3)$ & $39(0.3)$ & $47(0.4)$ \\
\hline \multirow[t]{2}{*}{ Residence } & Urban & $1277(10.4 \%)$ & $815(7.3)$ & $1,528(12.9)$ & $1,216(11.0)$ \\
\hline & Rural & $10,984(89.5)$ & $10,348(92.7)$ & $10,344(87.1)$ & $9,807(88.8)$ \\
\hline \multirow[t]{4}{*}{ Highest education } & Illiterate & $10,063(82.1)$ & 8838(79.1) & $8,227(69.3)$ & $7,284(66.1)$ \\
\hline & Primary & $1,596(13.1)$ & 1845(16.2) & $3,211(27.1)$ & $2,951(26.8)$ \\
\hline & Secondary & $573(4.7)$ & $427(3.8)$ & $266(2.2)$ & $514(4.7)$ \\
\hline & Higher & $28(0.2)$ & $43(0.3)$ & $168(1.4)$ & $274(2.5)$ \\
\hline \multirow[t]{4}{*}{ Marital status } & $\begin{array}{l}\text { Never } \\
\text { married }\end{array}$ & $64(0.5)$ & $37(0.3)$ & $78(0.7)$ & $57(0.5)$ \\
\hline & Married & $11,270(91.9)$ & $10,518(94.2)$ & $10,989(92.6)$ & $10,462(94.9)$ \\
\hline & Widowed & $189(1.5)$ & 183(1.6) & $229(1.9)$ & $384(3.5)$ \\
\hline & Divorced & $738(6.1)$ & $424(3.8)$ & $576(4.8)$ & $274(2.5)$ \\
\hline \multirow[t]{2}{*}{ Employment status } & Yes & $6,858(55.9)$ & $2,590(23.2)$ & $4,060(34.2)$ & $8,035(72.9)$ \\
\hline & No & $5,397(44.1)$ & $8,572(6.8)$ & $7,803(65.7)$ & $2,988(27.1)$ \\
\hline \multirow[t]{2}{*}{ Wealth quantile } & poorest & NA & $2,439(21.9)$ & $2,709(22.8)$ & $2,636(23.9)$ \\
\hline & poorer & NA & $2,356(21.1)$ & $2,658(22.4)$ & $2,519(22.9)$ \\
\hline
\end{tabular}




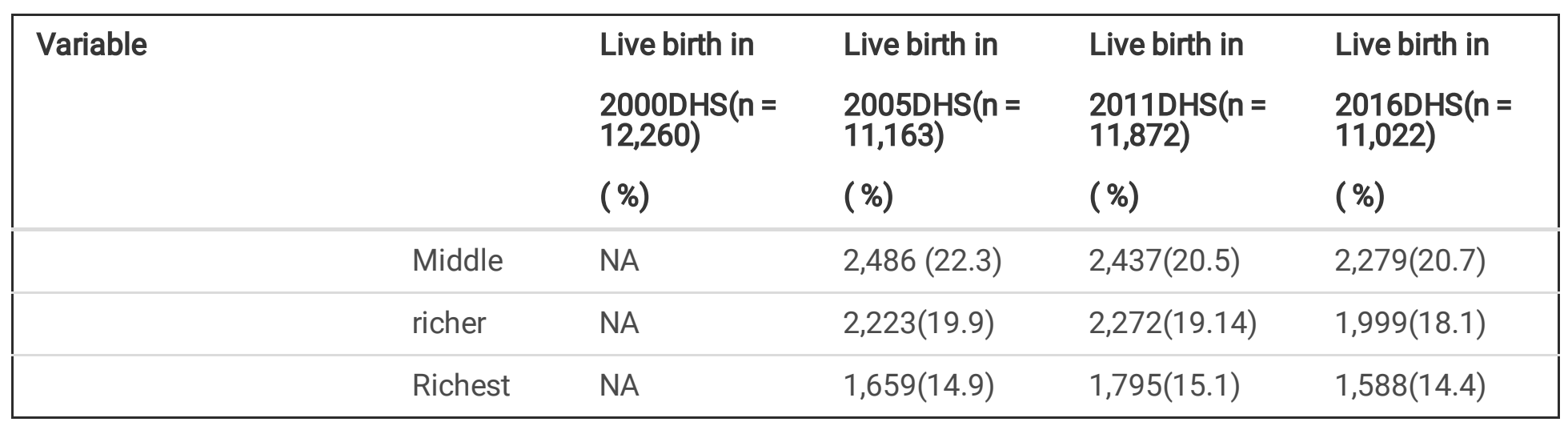

Child characteristics and maternal health service usage

The median BMI of women was similar across the four surveys, recent one (DHS 2016) was $21.1 \mathrm{~kg} / \mathrm{m} 2$, with a range between $53.6 \mathrm{~kg} / \mathrm{m} 2$ and $12.3 \mathrm{~kg} / \mathrm{m} 2$. Almost one-fifth of women had $1-3$ parity across the four surveys, the highest was in (DHS2011) 44.6\%. Furthermore, of all live births born from the interviewed women, more than half of them were single birth across four surveys. Among the birth order, fourth/higher-order births accounted for about half of all births (51.1\%). The percentage of women giving birth at home decreased from $94.9 \%$ in the first survey to $72.2 \%$ in the fourth survey. The percentage of women who had 1-4 ANC visits grew from 16.4 percent in 2000 to 30.9 percent in 2016 (Table 2). 
Table 2

Child and maternal characteristics and health service usage, finding from 2000 to 2016 DHS

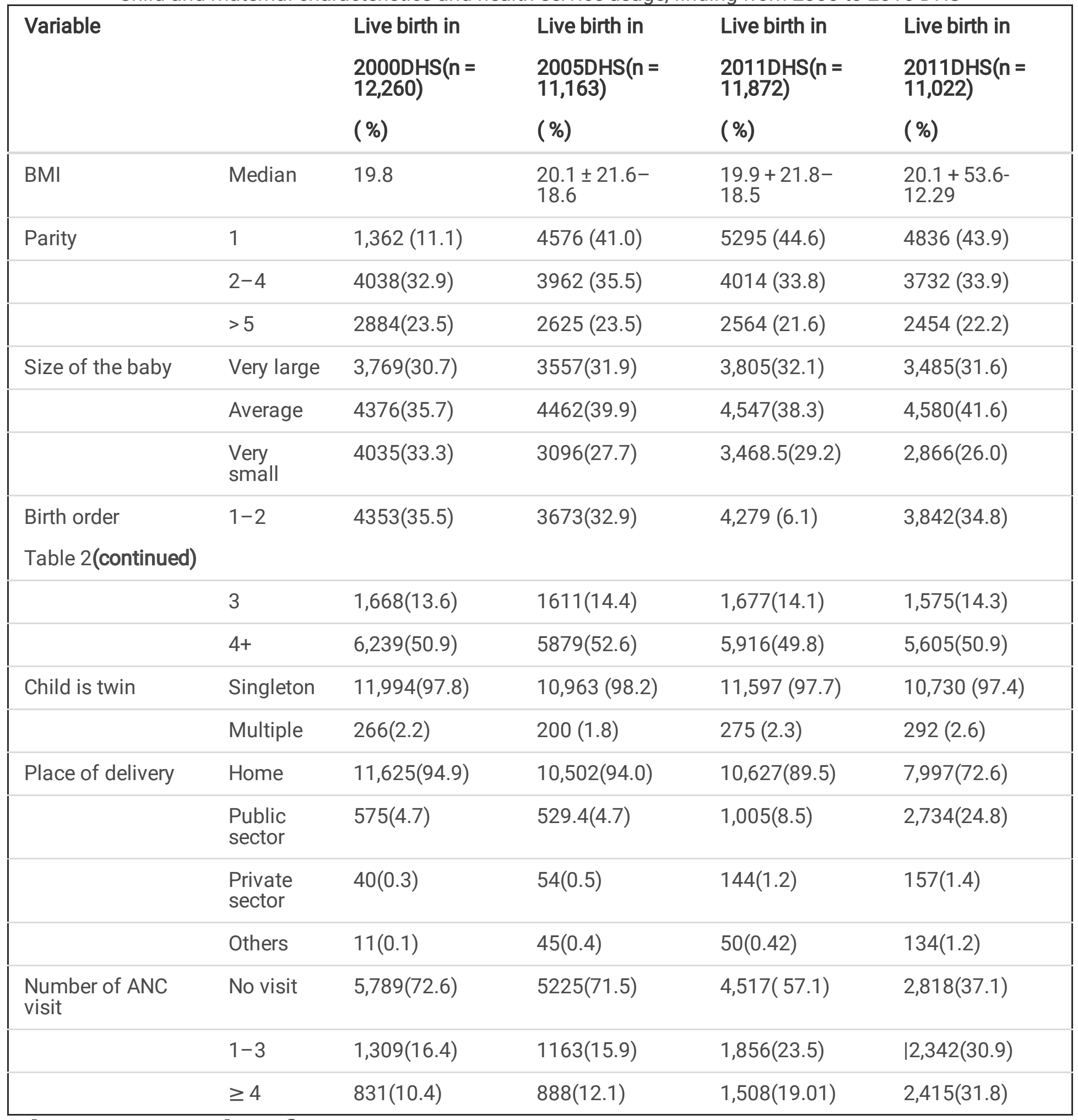

\section{The magnitude of cesarean section rate}

CS rate in urban area indicated $5.1 \%$ in $2000,9.4 \%$ in 2005 , and $10.6 \%$ in 2016 . Furthermore, in all four survey years, the percentage of CS increased among women with overweight (from 7.6\% in 2000 to $7.8 \%$ in 2016). Women of $>5$ parity (from $0.1 \%$ in 2000 to $0.4 \%$ in 2016), a number of ANC visit > 4 (from 1.8\% in 2000 to $7.5 \%$ in 2016 Table (3). The rate of CS delivery among women increased age group of $25-34$ and $35-49$ years of age ( $0.3 \%$ in 2000 to 1.9 
in 2016 and 0.1 in 2000 to 1.8 in 2016) survey period, respectively. Additionally, private health facilities show multiple pregnancies (Fig. 1). 
Table 3

The magnitude of cesarean section rate across the various characteristics of the respondents in Ethiopia, finding from 2000 to 2016

\begin{tabular}{|c|c|c|c|c|c|c|c|c|c|}
\hline \multirow[t]{3}{*}{ Variable } & & \multirow{2}{*}{\multicolumn{2}{|c|}{$\begin{array}{l}\text { Live birth in } \\
2000 \mathrm{DHS}(\mathrm{n}= \\
12,260)\end{array}$}} & \multicolumn{2}{|c|}{ Live birth in } & \multicolumn{2}{|c|}{ Live birth in } & \multicolumn{2}{|c|}{ Live birth in } \\
\hline & & & & \multicolumn{2}{|c|}{$\begin{array}{l}\text { 2005DHS }(n= \\
11,163)\end{array}$} & \multicolumn{2}{|c|}{$\begin{array}{l}\text { 2011DHS(n = } \\
11,872)\end{array}$} & \multicolumn{2}{|c|}{$\begin{array}{l}\text { 2016DHS(n= } \\
11,022)\end{array}$} \\
\hline & & \multicolumn{2}{|c|}{ (\%) $\mathrm{Cl}$} & \multicolumn{2}{|c|}{ (\%) $\mathrm{Cl}$} & \multicolumn{2}{|c|}{ (\%) Cl } & \multicolumn{2}{|c|}{ (\%) $\mathrm{Cl}$} \\
\hline \multirow[t]{3}{*}{ Age } & $18-24$ & 1.3 & $0.9,1.9$ & 1.2 & $0.8,1.7$ & 1.9 & $1.4,2.6$ & 1.7 & $1.2,2.5$ \\
\hline & $25-34$ & 0.3 & $0.2,0.5$ & 1 & $0.7,1.5$ & 1.1 & $0.8,1.5$ & 2.2 & $1.7,2.8$ \\
\hline & $35-49$ & 0.1 & $0.0,0.2$ & 0.5 & $0.2,1.2$ & 1.3 & $0.6,2.9$ & 1.9 & $1.1,3.2$ \\
\hline \multirow[t]{2}{*}{ Residence } & Urban & 5.1 & $3.7,7.1$ & 9.4 & $6.5,13.4$ & 8.1 & $6.3,10.5$ & 10.6 & $8.5,13.1$ \\
\hline & Rural & 0.2 & $0.1,0.3$ & 0.3 & $0.2,0.6$ & 0.5 & $0.3,0.8$ & 0.9 & $0.6,1.3$ \\
\hline \multirow{4}{*}{$\begin{array}{l}\text { Highest } \\
\text { education }\end{array}$} & Illiterate & 0.1 & $0.1,0.2$ & 0.4 & $0.2,0.6$ & 0.4 & $0.2,0.7$ & 0.7 & $0.4,1.1$ \\
\hline & Primary & 1.2 & $0.6,2.2$ & 0.9 & $0.5,1.6$ & 2.4 & {$[1.5,3.9]$} & 2.5 & $1.8,3.6$ \\
\hline & Secondary & 8.4 & $5.1,13.6$ & 12.1 & {$[8.5,16.8$} & 14.6 & $10.0,21.0$ & 6.3 & $4.2,9.5$ \\
\hline & Higher & 18.8 & $7.1,41.5$ & 23 & $11.7,40.1$ & 13.7 & $8.3,21.9$ & 20.8 & $15.7,26.9$ \\
\hline \multirow{4}{*}{$\begin{array}{l}\text { Marital } \\
\text { status }\end{array}$} & Never married & 3.9 & $0.6,20.5$ & 4.2 & $0.6,23.2$ & 7.2 & $2.3,20.1$ & 14.2 & $6.4,28.7$ \\
\hline & Married & 0.5 & $0.3,0.7$ & 0.9 & $0.7,1.2$ & 1.4 & $1.1,1.9$ & 1.8 & $1.5,2.3$ \\
\hline & Widowed & 2.5 & $0.4,12.6$ & 1.3 & $0.3,6.5$ & 1.2 & $0.4,4.3$ & 0.5 & $0.1,3.7$ \\
\hline & Divorced & 3.2 & $1.3,7.8$ & 1.9 & $0.8,4.2$ & 1.8 & $0.9,3.7$ & 3 & $1.5,5.8$ \\
\hline \multirow{2}{*}{$\begin{array}{l}\text { Employment } \\
\text { status }\end{array}$} & yes & 0.7 & $0.4,1.2$ & 1.6 & $1.0,2.5$ & 1.7 & $1.2,2.3$ & 3.1 & $2.4,4.2$ \\
\hline & No & 0.7 & $0.4,1.1$ & 0.8 & $0.6,1.1$ & 1.4 & $1.0,2.0$ & 1.5 & $1.1,2.0$ \\
\hline \multirow{6}{*}{$\begin{array}{l}\text { Wealth } \\
\text { quantile }\end{array}$} & poorest & NA & NA & 0 & $0.0,0.2$ & 7.2 & 2.3,20.1 & 0.6 & $0.2,1.4$ \\
\hline & poorer & NA & NA & 0.3 & $0.1,0.8$ & 1.4 & $1.1,1.9$ & 1 & $0.4,2.4$ \\
\hline & Middle & NA & NA & 0.2 & $0.1,0.5$ & 1.2 & $0.4,4.3$ & 1 & $0.5,2.0$ \\
\hline & richer & NA & NA & 0.5 & $0.2,1.0$ & 1.8 & $0.9,3.7$ & 1 & $0.5,1.9$ \\
\hline & Richest & NA & NA & 5.3 & $3.9,7.2$ & 7.2 & 2.3,20.1 & 8.1 & $6.6,9.9$ \\
\hline & $\begin{array}{l}\text { Table } 3 \\
\text { Continued) }\end{array}$ & & & & & & & & \\
\hline \multirow[t]{2}{*}{ BMI } & $\begin{array}{l}\text { normal } \\
(18.05-24.09\end{array}$ & 0.5 & $0.3,1.0$ & 0.7 & $0.4,1.2$ & 1 & $0.7,1.3$ & 1.6 & $1.2,2.1$ \\
\hline & $\begin{array}{l}\text { Underweight(< } \\
\text { 18.04) }\end{array}$ & 0.5 & $0.3,0.8$ & 0.6 & $0.2,1.7$ & 0.9 & $0.4,2.0$ & 0.9 & $0.3,2.5$ \\
\hline
\end{tabular}




\begin{tabular}{|c|c|c|c|c|c|c|c|c|c|}
\hline \multirow[t]{4}{*}{ Variable } & & \multirow{3}{*}{\multicolumn{2}{|c|}{$\begin{array}{l}\text { Live birth in } \\
2000 \mathrm{DHS}(\mathrm{n}= \\
12,260)\end{array}$}} & \multirow{2}{*}{\multicolumn{2}{|c|}{$\begin{array}{l}\text { Live birth in } \\
\text { 2005DHS(n= } \\
11,163)\end{array}$}} & \multirow{2}{*}{\multicolumn{2}{|c|}{$\begin{array}{l}\text { Live birth in } \\
2011 \mathrm{DHS}(\mathrm{n}= \\
11,872)\end{array}$}} & \multirow{2}{*}{\multicolumn{2}{|c|}{$\begin{array}{l}\text { Live birth in } \\
\text { 2016DHS( } \mathrm{n}= \\
11,022)\end{array}$}} \\
\hline & & & & & & & & & \\
\hline & \multirow[b]{2}{*}{$\begin{array}{l}\text { overweight (> } \\
25.00 \text { ) }\end{array}$} & & & \multicolumn{2}{|c|}{ (\%) $\mathrm{Cl}$} & \multicolumn{2}{|c|}{ (\%) $\mathrm{Cl}$} & \multicolumn{2}{|c|}{ (\%) $\mathrm{Cl}$} \\
\hline & & 7.6 & $3.1,17.5$ & 8 & $3.9,16.0$ & 8.6 & $5.8,12.5$ & 7.8 & $5.5,11.1$ \\
\hline \multirow[t]{3}{*}{ Parity } & $1-3$ & 1.5 & $1.1,2.1$ & 2 & $1.5,2.7$ & 2.7 & $2.1,3.3$ & 3.7 & $3.0,4.5]$ \\
\hline & $4-6$ & 0.1 & $0.0,0.3$ & 0.1 & $0.1,0.4$ & 0.7 & $0.3,1.5$ & 0.7 & $0.4,1.3$ \\
\hline & $>6$ & 0.1 & $0.0,0.3$ & 0.5 & $0.2,1.1$ & 0.2 & $0.1,0.6$ & 0.4 & $0.2,1.0$ \\
\hline \multirow{3}{*}{$\begin{array}{l}\text { Size of the } \\
\text { baby }\end{array}$} & Very large & 1 & $0.6,1.5$ & 1.3 & $0.9,2.0$ & 1.7 & $1.2,2.5$ & 2.6 & $1.9,3.5$ \\
\hline & Average & 0.7 & $0.4,1.1$ & 0.9 & $0.6,1.4$ & 1.6 & $1.0,2.6$ & 1.7 & $1.2,2.4$ \\
\hline & Very small & 0.5 & $0.3,0.9$ & 0.7 & {$[0.4,1.2$} & 1 & $0.7,1.5$ & 1.5 & $1.0,2.2$ \\
\hline \multirow[t]{3}{*}{ birth order } & $1-2$ & 1.8 & $1.3,2.6$ & 2.4 & $1.8,3.2$ & 2.9 & $2.3,3.7$ & 3.7 & $2.9,4.7$ \\
\hline & 3 & 0.1 & $0.0,0.3$ & 0.4 & $0.2,0.8$ & 1.1 & $0.6,1.9$ & 2.5 & $1.6,3.8$ \\
\hline & $4+$ & 0.1 & $0.0,0.2$ & 0.3 & $0.1,0.6$ & 0.6 & $0.3,1.1$ & 0.6 & $0.3,0.9$ \\
\hline \multirow[t]{2}{*}{ Child is twin } & Singleton & 0.7 & $0.5,0.9$ & 1 & $0.7,1.3$ & 1.4 & $1.1,1.8$ & 1.8 & $1.4,2.2$ \\
\hline & Multiple & 1.8 & $0.3,11.9$ & 3.3 & $1.2,8.8$ & 4.1 & $1.3,12.5$ & 7.5 & $3.4,15.8$ \\
\hline \multirow{2}{*}{$\begin{array}{l}\text { Place of } \\
\text { delivery }\end{array}$} & Public sector & 14.4 & $10.7,19.1$ & 18.9 & $15.1,23.5$ & 14.6 & $11.5,18.3$ & 6.5 & $5.3,8.1$ \\
\hline & Private sector & 7.9 & $3.0,19.3$ & 20 & $8.4,40.4$ & 20.1 & $14.0,28.1$ & 21.7 & $15.2,29.9$ \\
\hline \multirow{3}{*}{$\begin{array}{l}\text { Number of } \\
\text { ANC visit }\end{array}$} & No visit & 0.2 & $0.1,0.4$ & 0.2 & $0.1,0.4$ & 0.2 & $0.1,0.5$ & 0.5 & $0.2,1.2$ \\
\hline & $1-3$ & 1 & $0.4,2.6$ & 1.5 & $0.7,2.9$ & 2.4 & $1.5,3.8$ & 1.3 & $0.8,2.2$ \\
\hline & $\geq 4$ & 3.8 & $2.2,6.4$ & 6.3 & $4.6,8.5$ & 6 & $4.5,7.8$ & 5.7 & $4.6,7.0$ \\
\hline
\end{tabular}

\section{The trend of cesarean section}

In five DHS data (the 2019 mini DHS data was included) was a significant variation in trend the rate of CS observed in the Urban and rural part of Ethiopia. According to DHS report, the trend of CS in an urban area over the preceding 5 years of the surveys had increased from the level of $5.1 \%(95 \% \mathrm{Cl}: 3.7-7.1)$ in $2000,9.4 \%(95 \% \mathrm{Cl}: 6.5,13.4)$ in 2005, 8.1\% (95\% Cl: 6.3,10.5) in 2011, 10.6. (95\% Cl: 8.5 and13.1) in 2016 and $10.1(95 \%$ Cl: $(7.2,14.0)$ in 2019. There is an overlapping of the confidence interval in the year 2000 and 2005, and also 2011 and 2016. Similarly, the trend of CS in rural area had increased from the level of $0.2 \%$ (95\% Cl: $0.1-0.3)$ in $2000,0.3 \%(95 \% \mathrm{Cl}: 0.2,0.6)$ in 2005, $0.5 \%(95 \% \mathrm{Cl}: 0.3,0.8)$ in $2011,0.9 \%(95 \% \mathrm{Cl}: 0.3,1.6)$ in 2016 and $3.9 \%(95 \% \mathrm{Cl} 2.8,5.4)$ in 2019 . Based on the chisquare test for linear trend, the increment was statically significant, in urban $\left(X^{2}=20.72, p\right.$-value $\left.<0.0001\right)$ and rural $\left(X^{2}=52.72\right.$, $p$-value $\left.<0.0001\right)$ areas respectively. In addition, the rate sustainably increased among administration regions. For example, Addis Ababa had the highest percentage (24.1\%) in 2019 and the biggest growth from the year $2000(7.9 \%)$. The rate was statistically significant at $(p<0.0001)$ Fig. 2. 
Figure 3 presents a year-specific trend of the rate of CS rate, survey data illustrated the rate of CS in urban had risen from $5.8 \%$ in 1995 to $16 \%$ in 2019 . Similarly, the rate of CS in rural had risen from $0.001 \%$ in 1995 to $3 \%$ in 2019 . The overall increment CS rate was $0.8 \%$ from 1995 to $6 \%$ in 2019 . Based on the chi-square linear trend the rate was statistically significant at $(p<0.0001),(p<0.0001),(p<0.0001)$, in urban, rural, and overall, respectively. Further, the absolute change CS rate in urban areas from (1995-2019) was $10.2 \%$, whereas, the average annual rate of increased (AARI) from (1995-2019) was 4\%, in rural part from (1995-2019), 2.9\% and 6.8\% was the absolute change and AARI, respectively. The overall CS rate increment from (1995-to 2019) was $2.2 \%$ absolute change and $6.7 \%$ AARI.

\section{Factors associated with cesarean section delivery}

Table 4 shows the findings of a multi-level logistic regression study evaluating the relationship between CS with a variety of individual and community-level contextual factors (Model I-IV) using the recent 2016 DHS data. The association between the outcome and explanatory variables was examined by using bivariate regression analysis. The variables were included in the multi-level regression analysis based on their association at the bivariate level. Models I is empty model. Model II and III show the findings of individual and community-level variables; whereas, model IV presents the results of all variables in the multilevel regression model. The Intra-Cluster Correlation (ICC) in Model I (empty model) revealed 63.9\% variability in CS delivery which was related to community variations (between-cluster variability). Similarly, between cluster variability in Model II, $11.9 \%$ in Model III, and Model IV was $23.7 \%$ and $5.8 \%$, respectively. According to the Proportional Change in Variance (PCV's) findings, adding predictor variables to the empty model improved the explanation of factors related to CS delivery. Model II (individual-level variables) had a PCV of 92.3\%, Model III (community-level factors) had an $82.5 \%$ PCV, and Model IV (combined individual-and community-level factors) had a PCV of $96.6 \%$. Model IV reveals that individual and It is better identify the factors related to CS birth therefore variables like mother's age at birth, education, BMI, parity, birth order, ANC visit, type of pregnancy, residence, geographical region were statistically associated with CS delivery. Communitylevel characteristics account for over $97 \%$ of the variability in CS delivery between communities and so on. From the final model, the odds havening CS delivery by women age group 34-49 years 5.2 times more likely compared to those age group of $18-24$ years ( $A O R=5.23 ; 95 \% \mathrm{Cl}: 2.85,9.59$, p-value $<0.000)$. Those secondary and higher education were increased the odds of CS delivery by 2 and 4.1 times than no education $(\mathrm{AOR}=2.01 ; 95 \% \mathrm{Cl}: 1.17$, $3.56, \mathrm{p}$-value $<0.012)$ and $(\mathrm{AOR}=4.12 ; 95 \% \mathrm{Cl}: 2.33-7.29$, $\mathrm{p}$-value $<0.000)$ respectively. Women who gave birth to multiple pregnancies have increased the odds of CS delivery by 11.2 times as compared to that singleton (AOR = $11.12 ; 95 \% \mathrm{Cl}: 5.37,23.23$, p-value $<0.000)$. The odd of CS decline with increasing parity and birth order, a mother with 2-4 children CS lower by $46 \%$ as compared to one child (AOR $=0.54 ; 95 \% \mathrm{Cl}: 0.37,0.80, \mathrm{p}$-value $<0.002)$ and those with birth order of greater than 4 , the odds of having a decline by $58 \%$ as compared to those with birth order of one $(A O R=0.42 ; 95 \% \mathrm{Cl}: 0.21,0.84, \mathrm{p}$-value $<0.023)$. Further, for women's body mass index greater than 25 the odds of delivery was increased by 1.7 times than women who had normal body mass index (AOR $=1.73 ; 95 \% \mathrm{Cl}: 1.22,2.45$, $\mathrm{p}$ value $<0.002$ ). Women who had 1-3 and four or more ANC visits had higher odds of CS2,2 and 3.3 times than those women with no ANC visit $(\mathrm{AOR}=2.26$; $95 \% \mathrm{Cl}: 1.12,4.58$, p-value < 0.023$)$ and $(\mathrm{AOR}=3.34 ; 95 \% \mathrm{Cl}: 1.12,4.58$, p-value $<0.001)$ respectively.

The variation also observed CS delivery across the different regions in-country and residence. The odds of women's delivery by CS were increased in those women who were living Harari region by 3 times as compared to women who were livening Tigray region $(\mathrm{AOR}=3.00 ; 95 \% \mathrm{Cl}: 1.55,5.81$, $\mathrm{p}$-value $<0.001)$. The urban woman had 2.3 times higher $(A O R=2.28 ; 95 \% \mathrm{Cl}: 1.35-3.88, \mathrm{p}$-value < 0.002$)$ odds to deliver by CS compared to those women were living in the rural area

Page $12 / 22$ 
Table 4

Multilevel multivariable logistic regression output for of cesarean section rate among live births in Ethiopia 2016

\begin{tabular}{lllll} 
Variable & Null & Model II AOR (95\% & Model II AOR (95\% & $\begin{array}{l}\text { Model IV AOR (95\% } \\
\text { model }\end{array}$ \\
\cline { 2 - 2 } & $\mathrm{Cl})$ & $\mathrm{Cl})$ & $\mathrm{Cl}$
\end{tabular}

Mother's age at birth

$18-24$

$25-34$

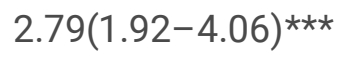

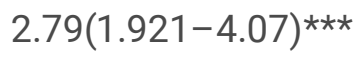

$35-49$

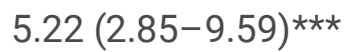

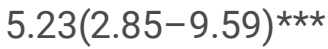

Highest educational

level

Illiterate

Primary

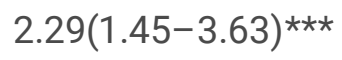

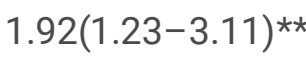

Secondary

$2.57(1.49-4.41)^{\star \star}$

$2.012(1.17-3.56)$ *

Higher

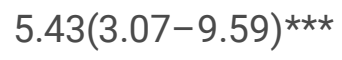

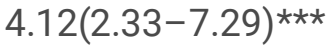

Marital Status

Never married

Married

$0.50(0.19-1.33)$

0.58(0.23-1.55)

Widowed

$0.12(.01-1.21)$

0.16(0.016-1.64)

Divorced

0.45(.15-1.35)

0.55(0.18-1.64)

Wealth quantile

poor

Middle

$1.11(0.56-2.21)$

1.04(0.53-2.079)

Rich

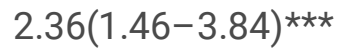

1.16(0.65-2.053)

BMI

normal (18.05-24.09)

Underweight(<18.04)

$0.47(0.25-0.88)$ *

0.53(0.28-1.00)

overweight (>25.00)

2.08(1.49-2.93***

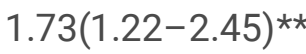

Parity

1

2-4

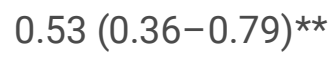

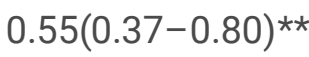

$>5$

$0.41(0.18-0.94)$

0.45(0.19-1.03)

birth order

${ }^{*} \mathrm{p}<0.05,{ }^{* *} \mathrm{p}<0.01, * \star * \mathrm{p}<0.001$. AIC Akaike's Information Criterion, BIC Bayesian Information Criterion, ICC Intra-Cluster Correlation, PCV Proportional Change in Variance, SE Standard Err 


\begin{tabular}{|c|c|c|c|c|}
\hline Variable & $\begin{array}{l}\text { Null } \\
\text { model }\end{array}$ & $\begin{array}{l}\text { Model II AOR (95\% } \\
\text { Cl) }\end{array}$ & $\begin{array}{l}\text { Model II AOR (95\% } \\
\text { Cl) }\end{array}$ & $\begin{array}{l}\text { Model IV AOR (95\% } \\
\mathrm{Cl})\end{array}$ \\
\hline \multicolumn{5}{|l|}{$1-2$} \\
\hline 3 & & $0.52(0.31-0.89)^{\star}$ & & $0.50(0.35-0.99)$ \\
\hline \multicolumn{5}{|c|}{ Table 4 (continued) } \\
\hline $4+$ & & $0.33(0.17-0.66)^{\star \star}$ & & $0.42(0.21-0.84)^{\star}$ \\
\hline \multicolumn{5}{|l|}{ Child is twin } \\
\hline \multicolumn{5}{|l|}{ Singleton } \\
\hline Multiple & & $\begin{array}{l}12.38(6.04- \\
25.34)^{\star \star \star}\end{array}$ & & $11.16(5.37-23.23)^{\star \star \star}$ \\
\hline \multicolumn{5}{|c|}{ Number of ANC visit } \\
\hline \multicolumn{5}{|l|}{ No visit } \\
\hline $1-3$ & & $2.71(1.34-5.46)^{\star \star}$ & & $2.26(1.12-4.58)^{\star}$ \\
\hline$\geq 4$ & & $4.23(2.15-8.33)^{\star \star \star}$ & & $3.34(1.67-6.66)^{\star \star}$ \\
\hline \multicolumn{5}{|l|}{ Residence } \\
\hline Urban & & & $\begin{array}{l}10.19(6.58- \\
15.80)^{\star \star \star}\end{array}$ & $2.28(1.35-3.88)^{\star \star}$ \\
\hline \multicolumn{5}{|l|}{ Rural } \\
\hline \multicolumn{5}{|l|}{ Region } \\
\hline \multicolumn{5}{|l|}{ Tigray } \\
\hline Affar & & & $0.28(0.09-0.81)^{\star}$ & $0.71(0.26-1.96)$ \\
\hline Amhara & & & $1.01(0.47-2.22)$ & $0.96(.45-2.04)$ \\
\hline Oromiya & & & $0.56(0.25-1.25)$ & $0.92(0.43-1.99)$ \\
\hline Somali & & & $0.11(.04-0.33)^{\star \star \star}$ & $0.39(0.12-1.25)$ \\
\hline Ben-Gumz & & & $0.45(0.16-1.24)$ & $0.610(.21-1.72)$ \\
\hline SNNP & & & $1.30(0.63-2.72)$ & $1.24(0.62-2.47)$ \\
\hline Gambela & & & $0.40(0.16-1.04)$ & $0.37(0.13-0.99)$ \\
\hline Harari & & & $3.11(1.53-6.33)^{\star \star}$ & $3.00(1.55-5.81)^{\star \star}$ \\
\hline Addis Ababa & & & $3.14(1.56-6.30)^{\star \star}$ & $1.51(0.81-2.81)$ \\
\hline Dire Dawa & & & $1.14(0.524-2.46)$ & $1.73(0.87-3.38)$ \\
\hline \multicolumn{5}{|c|}{ Random effect } \\
\hline $\begin{array}{l}\text { Community } \\
\text { variance(SE) }\end{array}$ & $5.83(0.93)$ & $0.45(0.22)$ & $1.02(0.25)$ & $0.21(0.21)$ \\
\hline
\end{tabular}




\begin{tabular}{|c|c|c|c|c|}
\hline Variable & $\begin{array}{l}\text { Null } \\
\text { model }\end{array}$ & $\begin{array}{l}\text { Model II AOR (95\% } \\
\mathrm{Cl})\end{array}$ & $\begin{array}{l}\text { Model II AOR (95\% } \\
\text { Cl) }\end{array}$ & $\begin{array}{l}\text { Model IV AOR (95\% } \\
\text { Cl) }\end{array}$ \\
\hline ICC & $63.9 \%$ & $11.99 \%$ & $23.73 \%$ & $5.76 \%$ \\
\hline PCV & Reference & 92.32 & 82.46 & 96.55 \\
\hline \multicolumn{5}{|l|}{ Model fitness } \\
\hline Log likelihood & -1194.06 & -750.55 & -1036.49 & -722.52 \\
\hline AIC & 2392.13 & 1549.10 & 2098.96 & 1515.06 \\
\hline BIC & 2406.68 & 1712.99 & 2193.53 & 1754.07 \\
\hline
\end{tabular}

\section{Discussion}

This study used the EDHS data to analyze the trend of CS rate and identify the factors associated with CS delivery. According to our findings, the CS rate increased from $0.8 \%$ from 1995 to $6 \%$ in 2019 over 24 years of the survey period indicates that CS availability has slightly improved, this finding comparable study conducted in Uganda 5.22\% (28), in Mozambique 4.7\% (19); Whereas, a study conducted in Egypt 40.1\%(29), Nepal 9\% (30), Bangladesh $63 \%$ (31), the low prevalence of CS utilization in present compared to above-mentioned countries. It might be due to, the facility and expertise for emergence and obstetrics service including CS delivery insufficient and/or sparsely scattered throughout the country, equipment and medicines in the emergency obstetric health centers are insufficient, lack of competent birth attendants and services as well as distances and poor landscape without adequate transportation could create a significant geographic barrier to emergency obstetric treatment(32).In addition to this, lacks information about CS delivery contributing to low acceptance of CS among Ethiopian women. For example, women may be fear mortality, anxiety about complications, a poor impression of CS as an unnatural technique of delivery, and the expensive expense of the surgery.

The study observed living in the urban area increase CS rate from 5.8\% (1995) to 16\%(2019) with an absolute change was $10.2 \%$; likewise, women who were living in the rural area CS rate increased from $0.001 \%$ (1995) to $3.9 \%$ ( 2015-2016)with absolute change was 3.8\%. Some studies support this finding like a study in Vietnam shows that living in an urban area doubles the likelihood of undergoing a CS (33). a similar finding in Nepal and Mozambique $(19,34)$. The higher CS rate in an urban area compared to that of the rural area because Ethiopia's health system is beset by a significant shortage of skilled health workers, doctors, and nurses in the rural area. The health workforce is disproportionately concentrated in urban regions; whereas, rural facilities are overworked, understaffed, and underequipped. The capital and large cities are home to all significant private and public health institutions, indicating a highly centralized distribution(35).In addition, the majority of cesarean births are performed in urban health facilities especially, private clinics(10). Although only $78.3 \%$ of the population lives in rural regions(36), health staff are concentrated in cities. Rural areas have a high concentration of less experienced doctors and community health workers. 
The finding of this study also indicates a considerable disparity in the service uptake of CS among maternal education, age, parity, body mass index, ANC visit, multiple pregnancy, birth order, and geographical region. Few studies support this finding $(18,29,34)$. This study finding revealed that mothers aged 25 or more had higher odds of delivering by CS compared to women aged less than 25-years old. This finding is supported by a study done in Vietnam(33), Mozambique(19), Egypt (29). The reason might be because the risk of delivery problems as well as the chance of premature birth and infant death, increased as women got older, excessive bleeding during labor, prolonged labor lasting more than 20 hours, and dysfunctional labor that does not progress to the next stage is such difficulties. Furthermore, diabetes and hypertension during pregnancy were more common in older pregnant women, this all may lead to increased cesarean section delivery $(37,38)$.

The odds of women who had completed primary, secondary, or higher education had more likely delivered by Caesarean section than women who had not been educated. This finding supports a study conducted by a global, regional, and national representative of 150 countries using secondary data from 1990-2014 (39), a similar study from Ethiopia (40), and Tanzania (41). The possible reason a higher degree of education enhances the possibility of CS delivery might be women who had received education are aware of the costs and benefits of using maternity services and also have more confidence and self-reliance for any decision provided by a health care provider which in turn, may raise the chance that could get Cs service. Besides, the evidence from health literature demonstrates, the fact that health literacy is linked to educational achievement could lead us to believe that highly educated women are more likely to seek health services such as CS delivery than their no educated counterparts (32, 42). ANC visit was found to be a significant predictor of cesarean delivery in our study. The women who had greater than four ANC visits during pregnancy had more than double the likelihood of delivery than those who did have ANC visits, a similar finding was reported from a study in Nepal (34) and Nigeria (18). The possible reason for this could be because women get more information about early detection of complications during pregnancy, birth preparedness, and complications at each ANC visit. As a result, women get all the information and can easily identify danger signs of pregnancy; hence, they may prefer methods of delivery, such as cesarean section. Further, our study also shows that compared to women who had one successful birth, those who had two and four successful births were less likely to undergo a caesarian section, similarly. some literature support this finding, study in Nigeria (18), population-based study in Ethiopia (10), Study in Ghana (43). The possible reason is that women who have not previously given spontaneous successful deliveries have had less experience on methods of delivery may fear labor pain related to vaginal delivery, thus, this leads to CS delivery.

In the present study, multiple pregnancies were significant factors for CS delivery, the odds of women who delivery twin pregnancy eleven times increased the likelihood of delivery by CS delivery as compared to singleton birth. Few studies support this finding in Nigeria (10) and Egypt (29). The possible reason that multiple pregnancies have been linked to obstetric complications like preterm labor, premature rupture of membranes, malposition, and malpresentation of the fetus, it also increased risks of complications to mother like gestational diabetes, gestational hypertension, preeclampsia, and intrahepatic cholestasis, all of those increase the likelihood of giving birth via CS $(44,45)$. Similarly, this study also investigates body mass index greater than 25 as significant predictors for CS delivery. Women with a body mass index greater than 25 more likely to deliver by cesarean as compared than women who had normal body mass index, little evidence support this finding in Egypt (29), population-based study in Ethiopia (12), the reason for the finding could be obese mothers have a higher risk of pregnancy complications like anemia, hypertension, pre-eclampsia, preterm delivery, emergency cesarean section, and gestational diabetes. Another study also investigated obesity increases the rate of with a rate of $20.7 \%$ in a normal weight control group, 33.8 percent in obese women, and $47.4 \%$ in morbidly obese women $(\mathrm{BMl}>35 \mathrm{~kg} / \mathrm{m} 2)(46)$ 
This research had some advantages. First, the research was based on big national representative datasets, giving it sufficient statistical power. Second, the study's estimates were completed after the data had been weighted to allow for probability sampling and non-response to make it representative at national and regional levels. One limitation of this study was, For trend analysis, the study employed 2019 mini demographic data; however, to assess factors that affect CS delivery, the study used 2016 data because the 2019 survey does not contain all the required information to run analysis, therefore, the authors mandatory to use 2016 data for factors variable.

\section{Conclusion}

In Ethiopia, both urban and rural area is CS rate was low which did not fall within the WHO's recommendation range. Although, a slight improvement was observed in the urban area. Factors associated with low prevalence and decrease the odd of CS delivery included residence in a rural area, lacks of ANC visits, and first parity. On the other hand, factors that are associated with higher prevalence and increased the odd of CS delivery included, region, multiple births, maternal overweight, higher educational status, women of $>25$ years. The current trend reflects unmet needs which are known risk factor that increases maternal and newborn mortality and it highlights the critical need for increased provision and better utilization of life-saving CS in Ethiopia. Therefore, enhanced availability and access to obstetric care services like CS delivery especially in rural areas need to be further pursued by meeting the WHO's recommendations. This will require increasing the number of comprehensive EOC facilities and supporting their equitable distribution as well as raising personnel strength and abilities, equipping and upgrading existing facilities, increasing skilled health workers in a rural area, strengthening equal distribution of health care workers in the rural and urban area.

The research also highlights the importance of addressing the geographic and socio-economic variables that contribute to Ethiopia's low CS prevalence; thus, empowering women and educating women, implementing health promotion programs aimed at preventing/reducing maternal overweight/obesity, increased co-services such as ANC usage and improving maternal awareness. All this could help to address the current problem.

\section{Abbreviations}

AOR: Adjusted Odds Ratio; Cl: Confidence Interval; CS: Caesarian Section; EDHS: Ethiopia Demographic and Health Survey; ICC: Intra Class Correlation Coefficient; OR: Odds Ratio; PVC: Proportional Change in Variance; EOC; emergency and obstetric care, WHO: world health organization, ANC: antenatal care, BMI: body mass index

\section{Declarations}

\section{Availability of data and material}

All datasets and material that used in the present study that supporting findings are available from the DHS program website

\section{Acknowledgments}

We'd like to thank the African Union Commission (AU) for funding this research. We'd also want to express our gratitude to the MEASURE DHS Program and ICF International for allowing us to use the EDHS data. We'd like to thank the academic and non-academic staff at the Pan African University Life and Earth Science Institute (PAULESI) at the University of Ibadan in Nigeria.

Page $17 / 22$ 


\section{Ethical approval and consent to participate}

The University College Hospital, University of Ibadan's research ethics committee gave their ethical clearance. All women who took part in Ethiopian demographic and health surveys gave their written informed consent.

\section{Authors' contribution}

RMA was participating in the conceptualization data extraction design, statistical analysis, and writing the first draft of the manuscript. 0.0.0 and YDB were all involved in the manuscript's conceptualization, statistical analysis, and editing. The final version of the manuscript was approved by all authors.

\section{Funding}

Not applicable, since it is secondary data

\section{Disclosure}

The author declare that they have no competing interest

\section{Consent for Publication}

Not applicable

\section{References}

1. medscape. Cesarean Delivery Dec 14, 2018. Available from: https://emedicine.medscape.com/article/263424overview.

2. Molina G, Weiser TG, Lipsitz SR, Esquivel MM, Uribe-Leitz T, Azad T, et al. Relationship Between Cesarean Delivery Rate and Maternal and Neonatal Mortality. Jama. 2015;314(21):2263-70.

3. Boerma T, Ronsmans C, Melesse DY, Barros AJ, Barros FC, Juan L, et al. Global epidemiology of use of and disparities in caesarean sections. The Lancet. 2018;392(10155):1341-8.

4. Betrán AP, Ye J, Moller AB, Zhang J, Gülmezoglu AM, Torloni MR. The Increasing Trend in Caesarean Section Rates: Global, Regional and National Estimates: 1990-2014. PloS one. 2016;11(2):e0148343.

5. Betrán AP, Torloni MR, Zhang J-J, Gülmezoglu A, Section WWGoC, Aleem H, et al. WHO statement on caesarean section rates. BJOG: An International Journal of Obstetrics \& Gynaecology. 2016;123(5):667-70.

6. Ye J, Zhang J, Mikolajczyk R, Torloni MR, Gülmezoglu AM, Betran AP. Association between rates of caesarean section and maternal and neonatal mortality in the 21st century: a worldwide population-based ecological study with longitudinal data. BJOG : an international journal of obstetrics and gynaecology. 2016;123(5):745-53.

7. Molina G, Weiser TG, Lipsitz SR, Esquivel MM, Uribe-Leitz T, Azad T, et al. Relationship Between Cesarean Delivery Rate and Maternal and Neonatal Mortality. Jama. 2015;314(21):2263-70.

8. Gjonej R, Poloska A, Keta M, Delija Z, Zyberaj F, Bezhani V, et al. The reasons of rising trend of cesarean section rate year after year. A retrospective study. International Journal of Nursing and midwifery. 2015;7(1):9-15. 
9. Harrison MS, Goldenberg RL. Cesarean section in sub-Saharan Africa. Maternal health, neonatology and perinatology. 2016;2(1):6.

10. Gebremedhin S. Trend and socio-demographic differentials of Caesarean section rate in Addis Ababa, Ethiopia: analysis based on Ethiopia demographic and health surveys data. Reproductive health. 2014;11(1):14.

11. Feng $X L, X u L$, Guo $Y$, Ronsmans $C$. Factors influencing rising caesarean section rates in China between 1988 and 2008. Bulletin of the World Health Organization. 2012;90:30-9A.

12. Yisma E, Smithers LG, Lynch JW, Mol BW. Cesarean section in Ethiopia: prevalence and sociodemographic characteristics. J Matern Fetal N. 2019;32(7):1130-5.

13. Manyeh AK, Amu A, Akpakli DE, Williams J, Gyapong M. Socioeconomic and demographic factors associated with caesarean section delivery in southern Ghana: evidence from INDEPTH network member site. BMC pregnancy and childbirth. 2018;18(1):405.

14. Dikete M, Coppieters Y, Trigaux PFJ, Englert Y, Simon P, Zhang W. Variation of caesarean section rates in SubSaharan Africa: A literature review.

Journal of Gynecological Research and Obstetrics August.

15. EDHS E. demographic and health survey 2016: key indicators report. The DHS Program ICF. 2016;363:364.

16. EDHS E. demographic and health survey 2000: key indicators report. The DHS Program ICF. 2000:206.

17. Ghana Statistical Service GHS, ICF International. Ghana demographic and health survey 2014. Rockville, Maryland, USA: GSS, GHS, and ICF International. 2015.

18. Adewuyi EO, Auta A, Khanal V, Tapshak SJ, Zhao Y. Cesarean delivery in Nigeria: prevalence and associated factors-a population-based cross-sectional study. BMJ open. 2019;9(6):e027273-e.

19. Long Q, Kempas T, Madede T, Klemetti R, Hemminki E. Caesarean section rates in Mozambique. BMC pregnancy and childbirth. 2015;15:253-.

20. USAID. Maternal, Neonatal and Child Health January 04, 2022. Available from: https://www.usaid.gov/ethiopia/global-health/maternal-and-child-health.

21. Gutema $H$, Shimye A. cesarean section and associated factors at mizan aman general hospital, southwest Ethiopia. J Gynecol Obstet. 2014;2(3):37-41.

22. Tsegaye $H$, Desalegne $B$, Wassihun B, Bante A. Prevalence and associated factors of caesarean section in Addis Ababa hospitals, Ethiopia. The Pan African medical journal. 2019;34.

23. Yisma E, Smithers LG, Lynch JW, Mol BW. Cesarean section in Ethiopia: prevalence and sociodemographic characteristics. The Journal of Maternal-Fetal \& Neonatal Medicine. 2019;32(7):1130-5.

24. bank tw. The world bank Ethiopia Jul 15, 2021. Available from:

https://www.worldbank.org/en/country/ethiopia/overview\#1.

25. Demographic EE. Health Survey 2011. Central Statistical Agency. Adis Abab, Ethiopia. 2011. 
26. Macro O. Central Statistical Agency Addis Ababa, Ethiopia. 2006.

27. Dean A, SULLIVAN K, Soe M, Sullivan K. OpenEpi: open source epidemiologic statistics for public health, version 2.3.1. scienceopencom. 2013.

28. UDHS I. Uganda demographic and health survey. Uganda Bureau of Statistics, Kampala Uganda. 2011.

29. Al Rifai RH. Trend of caesarean deliveries in Egypt and its associated factors: evidence from national surveys, 2005-2014. BMC pregnancy and childbirth. 2017;17(1):417-.

30. Acharya K, Paudel YR. Trend and Sociodemographic Correlates of Cesarean Section Utilization in Nepal: Evidence from Demographic and Health Surveys 2006-2016. BioMed research international. 2021;2021:8888267-.

31. Haider MR, Rahman MM, Moinuddin M, Rahman AE, Ahmed S, Khan MM. Ever-increasing Caesarean section and its economic burden in Bangladesh. PloS one. 2018;13(12):e0208623-e.

32. Fesseha N, Getachew A, Hiluf M, Gebrehiwot Y, Bailey P. A national review of cesarean delivery in Ethiopia. International Journal of Gynecology \& Obstetrics. 2011;115(1):106-11.

33. de Loenzien M, Schantz C, Luu BN, Dumont A. Magnitude and correlates of caesarean section in urban and rural areas: A multivariate study in Vietnam. PloS one. 2019;14(7):e0213129-e.

34. Bhandari AKC, Dhungel B, Rahman M. Trends and correlates of cesarean section rates over two decades in Nepal. BMC pregnancy and childbirth. 2020;20(1):763-.

35. A A, C W. IMPROVING HEALTH SYSTEM EFFICIENCY. world health organization. Geneva 2015.

36. data twb. Rural population (\% of total population) - Ethiopia 2020. Available from:

https://data.worldbank.org/indicator/SP.RUR.TOTL.ZS?locations=ET.

37. Rydahl E, Declercq E, Juhl M, Maimburg RD. Cesarean section on a rise-Does advanced maternal age explain the increase? A population register-based study. PloS one. 2019;14(1):e0210655-e.

38. Wang Z, Yang T, Fu H. Prevalence of diabetes and hypertension and their interaction effects on cardiocerebrovascular diseases: a cross-sectional study. BMC public health. 2021;21(1):1224.

39. Betrán AP, Ye J, Moller A-B, Zhang J, Gülmezoglu AM, Torloni MR. The Increasing Trend in Caesarean Section Rates: Global, Regional and National Estimates: 1990-2014. PloS one. 2016;11(2):e0148343-e.

40. Beyene MG, Zemedu TG, Gebregiorgis AH, Ruano AL, Bailey PE. Cesarean delivery rates, hospital readiness and quality of clinical management in Ethiopia: national results from two cross-sectional emergency obstetric and newborn care assessments. BMC pregnancy and childbirth. 2021;21(1):571.

41. Shibre G, Zegeye B, Ahinkorah BO, Keetile M, Yaya S. Magnitude and trends in socio-economic and geographic inequality in access to birth by cesarean section in Tanzania: evidence from five rounds of Tanzania demographic and health surveys (1996-2015). Archives of public health = Archives belges de sante publique. 2020;78:80-.

42. Logan RA, Wong WF, Villaire M, Daus G, Parnell TA, Willis E, et al. Health literacy: A necessary element for achieving health equity. NAM Perspect. 2015;24:1-9.

Page 20/22 
43. Manyeh AK, Amu A, Akpakli DE, Williams J, Gyapong M. Socioeconomic and demographic factors associated with caesarean section delivery in Southern Ghana: evidence from INDEPTH Network member site. BMC pregnancy and childbirth. 2018;18(1):405-.

44. Jonsson M. Induction of twin pregnancy and the risk of caesarean delivery: a cohort study. BMC pregnancy and childbirth. 2015;15(1):136.

45. Schulze G, Radzuweit H. [Indication for caesarean section for multiple pregnancy (author's transl)]. Zentralblatt fur Gynakologie. 1981;103(6):347-54.

46. Nkoka O, Ntenda PAM, Senghore T, Bass P. Maternal overweight and obesity and the risk of caesarean birth in Malawi. Reproductive health. 2019;16(1):40.

\section{Figures}

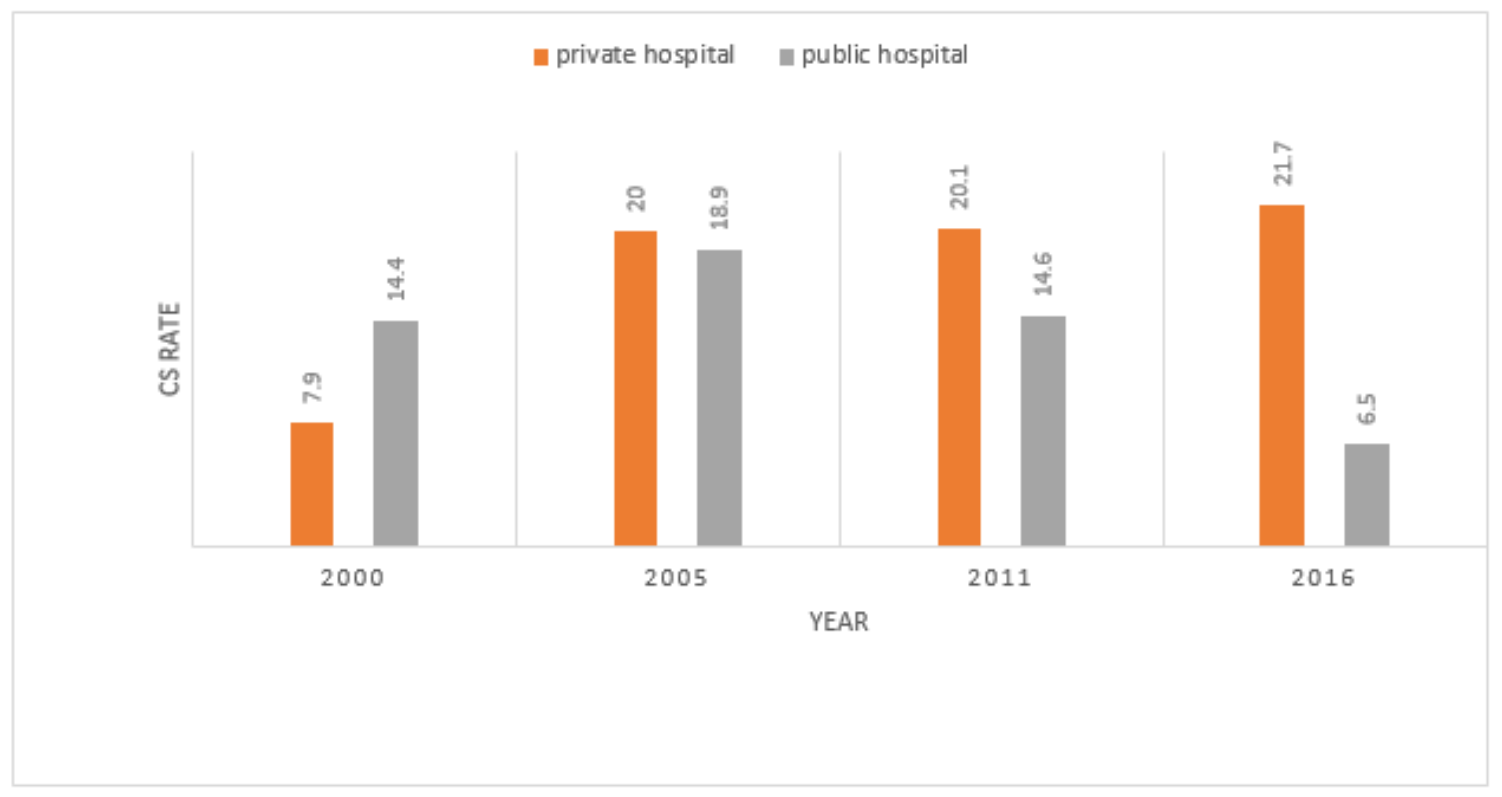

Figure 1

Magnitude of CS rate among private hospital, public hospital (200-2016) survey ye 


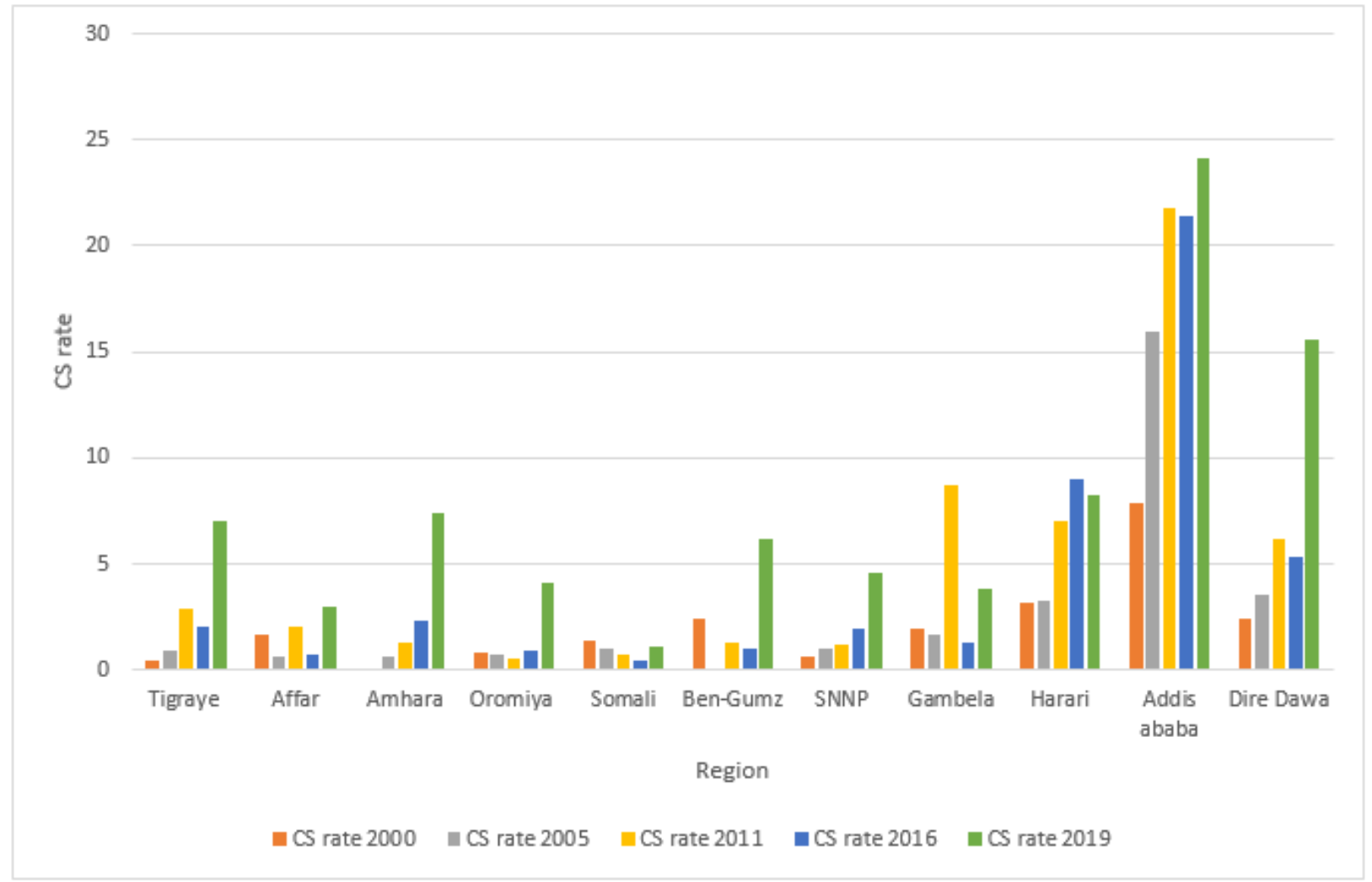

Figure 2

The trend of CS rate across the administrative region from (2000-20019) survey year

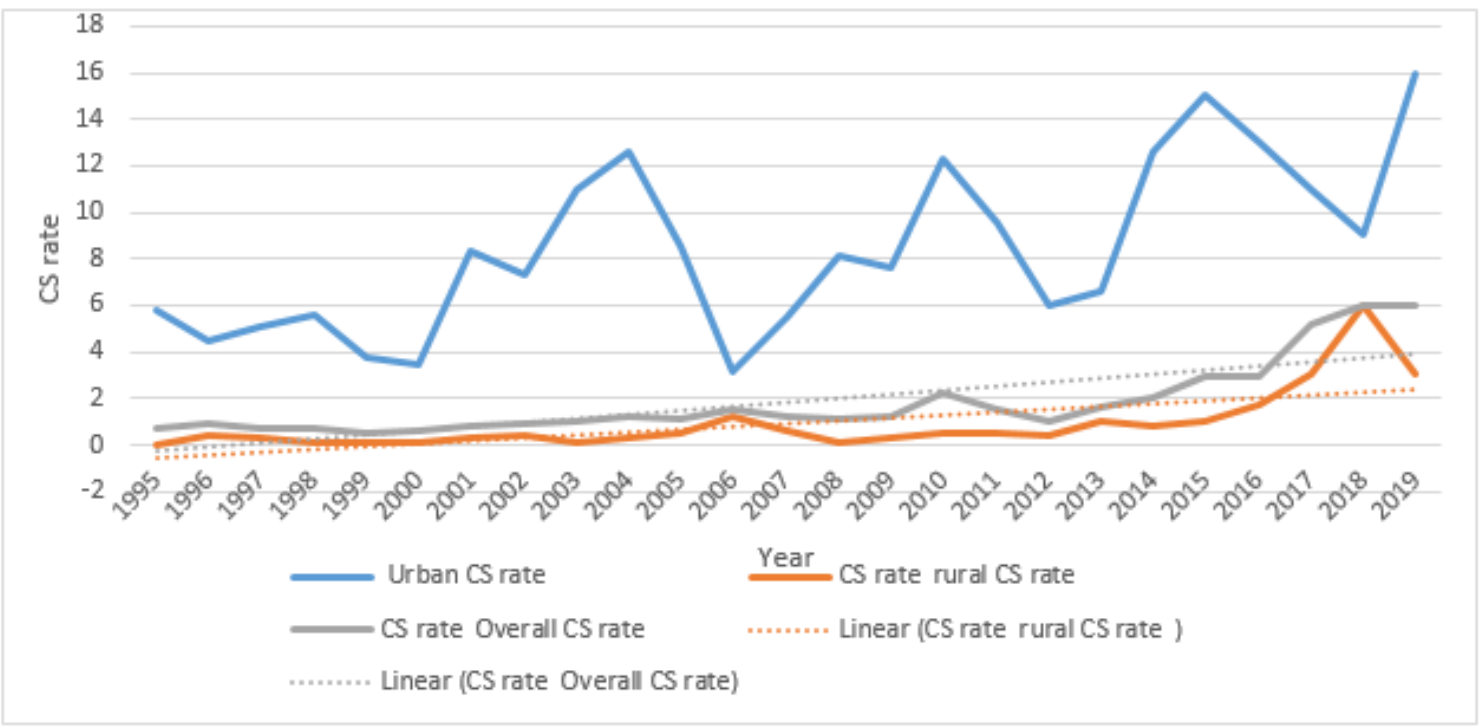

\section{Figure 3}

Trend of CS rate in the Urban and rural part of Ethiopia data from (1995-2019) 